CLINICAL STUDY

\title{
The PPAR- $\gamma$ Pro12Ala polymorphism associates with weight gain during GH-treatment in short children born small for gestational age
}

\author{
Sandra W K de Kort and Anita C S Hokken-Koelega \\ Division of Endocrinology, Department of Paediatrics, Erasmus University Medical Center, Sophia Children's Hospital, Room number SB-2603, \\ Dr Molewaterplein 60, 3015 GJ Rotterdam, The Netherlands
}

(Correspondence should be addressed to SW K de Kort; Email: s.dekort@erasmusmc.nl)

\begin{abstract}
Context: Short children born small for gestational age (SGA) have a lean phenotype with lower insulin sensitivity and higher blood pressure. GH treatment results in weight gain, and a decrease in blood pressure and insulin sensitivity. However, not all children respond in the same way. The Pro12Ala polymorphism of the peroxisome proliferator-activated receptor (PPAR- $\gamma$ ) gene is inversely associated with body mass index (BMI), changes in BMI and the risk to develop type 2 diabetes mellitus.

Objective: To analyze the contribution of the PPAR- $\gamma$ Pro12Ala polymorphism to GH induced changes in determinants of metabolic and cardiovascular disease in short SGA children.

Methods: PPAR- $\gamma$ was genotyped in 238 Caucasian short SGA children (mean age 7.5 years). Height, weight, blood pressure, and serum lipids were measured before start and during 4 years of GH treatment. In addition, glucose homeostasis by homeostasis model assessment insulin resistance ratio (HOMA-IR) $(n=148)$ and by frequently sampled i.v. glucose tolerance test $(n=51)$, and body composition by dual energy X-ray absorptiometry $(n=79)$ were measured.

Results: At baseline, the Ala12 allele was not associated with any determinant of metabolic and cardiovascular disease. After 4 years of GH treatment, the increase in weight for height SDS and BMI SDS was significantly greater in carriers of an Ala12 allele than in noncarriers. The change in all other parameters was not associated with Pro12Ala genotype.

Conclusion: The Ala12 variant of the PPAR- $\gamma$ gene is associated with higher weight gain during GH treatment but not with changes in determinants of metabolic and cardiovascular diseases in Caucasian subjects born SGA.
\end{abstract}

European Journal of Endocrinology 162 49-52

\section{Introduction}

GH treatment may be a modifier of the association between polymorphisms in the peroxisome proliferators-activated receptor $\gamma(P P A R-\gamma)$ gene and glucose homeostasis and the risk of type 2 diabetes mellitus $(\mathrm{DM})$ in later life. PPAR- $\gamma$ is a nuclear hormone receptor that controls genes involved in adipogenesis, and lipid and glucose metabolism (1). The Ala12 variant of the $P P A R-\gamma$ gene has been associated with improved insulin sensitivity and a lower risk for type 2 DM compared with the Pro12Pro genotype (2). In contrast, in a study in overweight individuals with impaired glucose tolerance (3) and in young adults born small for gestational age (SGA) (4), the Ala12 allele was associated with an increased risk for type $2 \mathrm{DM}$.

Results about the association of the Ala12 variant with body mass index (BMI) are conflicting. The Ala12 variant has been associated with a higher BMI $(5,6)$ and a tendency to gain weight over time $(7)$.
However, in subjects with a normal body weight, the Ala12Ala genotype was associated with a lower BMI and a lower increase in BMI at follow-up (8), and in a meta-analysis of subjects with a mean BMI $<27 \mathrm{~kg} / \mathrm{m}^{2}$, there was no significant difference in BMI between genotype groups (6). Size at birth also interacts with the effect of the Ala 12 allele. In young adults who were born SGA, increased BMI amplified the effect of PPAR- $\gamma$ polymorphism on glucose homeostasis, while in those born appropriate for gestational age there was not such an association (4). These conflicting results regarding associations of the Ala12 allele with insulin resistance and BMI demonstrate that the allele has a different effect in different environments, and that environmental factors may play a role to increase the genetic effect of PPAR $-\gamma$ on metabolic risk factors.

Subjects born SGA might have an increased risk to develop type $2 \mathrm{DM}$ in later life (9), particularly those with catch-up in weight (10). It is, however, unknown whether this increased risk is genetically or 
environmentally determined or by a combination of both. Most children with short stature who were born SGA are nowadays treated with GH. GH treatment generally results in weight gain, a decrease in blood pressure, serum lipid levels, and insulin sensitivity $(11,12)$. Also, there is a compensatory increase in insulin secretion (11). However, not all children respond in the same way. Since the PPAR- $\gamma$ gene was associated with BMI, glucose homeostasis, and atherosclerosis (1), genotyping might indicate which children are less capable to compensate for the effects of $\mathrm{GH}$ treatment on metabolic and cardiovascular risk factors and are thus more at risk to develop adult diseases.

The present study aimed to investigate whether PPAR- $\gamma$ polymorphisms correlate with changes in the metabolic and cardiovascular profile during GH treatment. To investigate this question, we performed genotyping of the PPAR- $\gamma$ gene, measurements of anthropometry, blood pressure, serum lipids, frequently sampled i.v. glucose tolerance tests (FSIGTs), and calculations of HOMA-IR in 238 short children who were born SGA and treated with GH.

\section{Subjects and methods}

\section{Subjects and study design}

The study group comprised 238 children (124 boys) with short stature (height SDS for age and gender $<-2$ (13)) who were born SGA (birth length and/or birth weight SDS $<-2.0$ for gestational age (14)) and treated with biosynthetic GH at a dose of $1 \mathrm{mg} / \mathrm{m}^{2}$ body surface area per day. Inclusion criteria have previously been described $(15,16)$. Height, weight, blood pressure, and serum lipids were measured before the start and during 4 years of GH treatment as previously described (17). In addition, glucose homeostasis by HOMA-IR $(n=148)$ and by FSIGT $(n=51)(11,18)$, and body composition by dual energy X-ray absorptiometry scans (DEXA, type Lunar DPX-L, GE Healthcare, Madison, WI, USA) (17) $(n=79)$ were measured. The Medical Ethics Committees of Erasmus Medical Center, Rotterdam, and the other participating centers approved all studies and written informed consent was obtained from all participants and their parents.

\section{Genotyping}

Genomic DNA was extracted from samples of peripheral venous blood according to salting out procedure (19). Genotyping of the PPAR- $\gamma$ gene Pro12ala polymorphism (rs1801282) was performed using the Taqman allelic discrimination assay. PCR was performed in 384 wells PCR plates in an ABI 9700 PCR system (Applied Biosystems Inc., Foster City, CA, USA) and consisted of initial denaturation for $10 \mathrm{~min}$ at $95^{\circ} \mathrm{C}$ and 40 cycles with denaturation of $15 \mathrm{~s}$ at $92{ }^{\circ} \mathrm{C}$ and annealing and extension for $60 \mathrm{~s}$ at $60^{\circ} \mathrm{C}$. Results were analyzed by ABI Taqman $7900 \mathrm{HT}$ using the sequence detection system 2.22 software (Applied Biosystems Inc).

\section{Statistical analysis}

Genotype distributions for significant departure from the Hardy-Weinberg equilibrium were calculated using the $\chi^{2}$ test. To assess longitudinally measured growth and metabolic characteristics from the start

Table 1 Patient characteristics before the start of GH treatment.

\begin{tabular}{|c|c|c|c|c|}
\hline & All $(n=238)$ & Pro/Pro $(n=168)$ & Pro/Ala or Ala/Ala $(n=70)$ & $P$ value \\
\hline Height SDS & $-2.98(0.7)$ & $-2.97(0.7)$ & $-3.01(0.7)$ & 0.72 \\
\hline Weight SDS $S_{\text {height }}$ & $-1.14(1.2)$ & $-1.16(1.3)$ & $-1.09(1.0)$ & 0.68 \\
\hline BMI SDS $_{\text {age }}$ & $-1.25(1.0)$ & $-1.29(1.0)$ & $-1.16(0.9)$ & 0.36 \\
\hline Body fat $\%$ & $12.68(7.0)$ & $12.83(7.7)$ & $12.32(5.0)$ & 0.77 \\
\hline Body fat $\%$ SDS $_{\text {age }}$ & $-0.76(1.0)$ & $-0.76(1.1)$ & $-0.76(1.0)$ & 1.00 \\
\hline Body fat $\%$ SDS $_{\text {height }}$ & $-0.77(1.3)$ & $-0.79(1.4)$ & $-0.73(1.2)$ & 0.87 \\
\hline LBM SDS $_{\text {age }}$ & $-2.49(0.7)$ & $-2.54(0.8)$ & $-2.39(0.4)$ & 0.38 \\
\hline LBM SDS & $-0.87(1.9)$ & $-1.03(1.9)$ & $-0.50(1.8)$ & 0.25 \\
\hline Systolic bp SDS & $1.0(1.1)$ & $1.0(1.1)$ & $1.2(1.1)$ & 0.24 \\
\hline Diastolic bp SDS & $0.3(1.0)$ & $0.2(1.0)$ & $0.4(1.1)$ & 0.36 \\
\hline F glucose $(\mathrm{mmol} / \mathrm{l})$ & $4.7(0.6)$ & $4.7(0.6)$ & $4.7(0.6)$ & 0.73 \\
\hline F insulin (pmol/l) & $24.0(14.0-36.0)$ & $25.0(14.0-40.0)$ & $30.0(15.0-48.0)$ & 0.39 \\
\hline HOMA-IR & $0.4(0.3-0.7)$ & $0.5(0.3-0.8)$ & $0.6(0.3-0.9)$ & 0.31 \\
\hline $\mathrm{Si}^{*} 10^{-4} / \mathrm{min}(\mu \mathrm{U} / \mathrm{ml})$ & $13.4(9.9-19.0)$ & $12.2(7.7-18.4)$ & $12.1(8.9-16.0)$ & 0.76 \\
\hline AIR (mU/l) & $267(180-352)$ & $214(170-355)$ & $317(266-440)$ & 0.11 \\
\hline $\mathrm{DI}\left(\mathrm{AIR}{ }^{\star} \mathrm{Si}\right)$ & 3139 (2575-4715) & $2880(2190-4600)$ & 3115 (2671-4671) & 0.32 \\
\hline Cholesterol (mmol/l) & $4.3(0.8)$ & $4.3(0.8)$ & $4.2(0.7)$ & 0.69 \\
\hline $\mathrm{HDL}(\mathrm{mmol} / \mathrm{l})$ & $1.5(0.4)$ & $1.4(0.4)$ & $1.5(0.4)$ & 0.91 \\
\hline LDL (mmol/l) & $2.4(0.7)$ & $2.4(0.7)$ & $2.4(0.6)$ & 0.69 \\
\hline Triglycerides (mmol/l) & $0.8(0.4)$ & $0.8(0.3)$ & $0.8(0.5)$ & 0.69 \\
\hline
\end{tabular}

Values are expressed as mean (S.D.) or as median (interquartile range). Data with a skewed distribution were log transformed before analysis with $t$-tests. LBM, lean body mass; bp, blood pressure; F, fasting; HOMA-IR, insulin resistance index; Si, insulin sensitivity; AIR, acute insulin response; DI, disposition index. $n=79$ for body fat \% and LBM; $n=225$ for blood pressure; $n=148$ for F glucose, F insulin, and HOMA-IR; $n=136$ for lipid levels; $n=51$ for Si, AIR, and DI. 
of $\mathrm{GH}$ treatment to 4 years after the start of treatment, we performed repeated measures regression analysis as previously described $(20,21)$. The models can be written as: outcome variable $=\beta_{0}+\beta_{1} *$ age + $\beta_{2}{ }^{*}$ gender $+\beta_{3}{ }^{*}$ puberty $+\beta_{4}{ }^{*}$ study duration $+\beta_{5}{ }^{*}$ genotype $+\beta_{6}{ }^{*}$ genotype*study duration.

Statistical significance was defined as $P<0.05$. Analyses were performed using the statistical package SPSS (version 15.0; SPSS Inc., Chicago, IL, USA) for Windows. SAS 8.2 (SAS Institute Inc., Cary, NC, USA) was used for repeated measures of variance analyses.

\section{Results}

The genotype distribution was Pro12Pro 70.6\%, Pro 12 Ala $26.9 \%$, and Ala12Ala $2.5 \%$ and was not different from the Hardy-Weinberg expectations $\left(\chi^{2}=0.001, P=0.97\right)$. The frequency of the Ala12 allele was $16 \%$, as reported in literature $(3,22)$. Mean (s.D.) age was 7.5 (2.9) years, birth weight SDS -2.27 (1.1), and birth length SDS -3.15 (1.4). No significant differences in age, gender distribution, size at birth, anthropometry, body composition, blood pressure, glucose homeostasis, and serum lipid levels were observed between the Ala12 carriers and noncarriers (Table 1). Twenty-three children (9.7\%) were in puberty at the start of study. The proportion of pubertal subjects was similar in both genotype groups $(P=0.91)$, and all results were similar when pubertal subjects were excluded.

During 4 years of $\mathrm{GH}$ treatment, the increase in weight $\mathrm{SDS}_{\text {height }}(0.9$ vs 0.6 SDS increase, $P=0.02)$ and in BMI SDS (0.6 vs 0.4 SDS increase, $P=0.03$ ) was greater in carriers of Ala12 than in noncarriers. The change in all other evaluated parameters was not significantly different between carriers and noncarriers of the Ala12 allele. The genotype distribution of the Pro12Ala polymorphism was not significantly different for children with a change in weight $\operatorname{SDS}_{\text {height }}(n=186)$ or BMI SDS $(n=172)>0$, and children with a change in weight $\operatorname{SDS}_{\text {height }}\left(\chi^{2}=2.23, P=0.14\right)$ or BMI SDS $\left(\chi^{2}=1.79, P=0.18\right)$ of $\leq 0$. In the subgroup of 79 children with a DEXA scan, the Pro12Ala polymorphism was not associated with the change in body fat \% SDS or the change in lean body mass SDS. However, in this much smaller group, weight SDS $_{\text {height }}$ and BMI SDS were also not associated with the Pro12Ala polymorphism, which might indicate a power problem in the relatively small DEXA group.

\section{Discussion}

In this study, we demonstrated that the PPAR- $\gamma$ Pro12Ala polymorphism was associated with a greater increase in weight SDS and BMI SDS during GH treatment of short SGA children. An explanation for this observation might be that the Ala12 allele facilitates fat accumulation. In a smaller subgroup with DEXA scans, we found no support for this hypothesis. In SGA children who caught up to a normal height and subjects with type 2 DM or obesity $(4,22-26)$, results about the association between Pro12Ala and estimates of glucose homeostasis and blood pressure have been conflicting. A population of short SGA children had not been studied yet. Among the risk factors that potentiate the insulin resistance associated with low birth weight, obesity is very important (10) but short SGA subjects are usually lean. As the association of PPAR- $\gamma$ Pro12Ala with insulin sensitivity might be mediated through body weight, it is important to study short SGA subjects separately. We found no direct association between PPAR $-\gamma$ Pro12Ala genotype and glucose homeostasis or blood pressure.

In conclusion, our data demonstrate the possible involvement of the PPAR- $\gamma$ Pro12Ala polymorphism in weight gain during GH treatment in short SGA children. The polymorphism was not associated with determinants of metabolic and cardiovascular disease, either at baseline or during GH treatment.

\section{Declaration of interest}

The authors declare that there is no conflict of interest that could be perceived as prejudicing the impartiality of the research reported.

\section{Funding}

This was an investigator-initiated study, which received independent research grants from Novo Nordisk Farma B.V. and Pfizer B.V., The Netherlands.

\section{Acknowledgements}

We greatly acknowledge Mrs C Bruinings-Vroombout, Mrs M Huibregtse-Schouten, Mrs J van Houten, Mrs J van Nieuwkasteele, Mrs J Dunk and Mrs E Lems, research nurses, for their assistance and help with data collection; Mrs J P Sluimer for performing and analyzing the DEXA measurements, Dr W H Hackeng for his glucose and insulin assays, M A J de Ridder for her help with the statistical analysis, and Dasha Gorbenko Del Blanco for her help with the genetics. We also greatly acknowledge the participating physicians: E G A H van Mil, Free University Hospital Amsterdam, The Netherlands; J C Mulder, Rijnstate Hospital, Arnhem, The Netherlands; R J H Odink and J J J Waelkens, Catharina Hospital, Eindhoven, The Netherlands; W M Bakker-van Waarde, University Medical Center Groningen, Groningen, The Netherlands; W H Stokvis, B Bakker, Leiden University Medical Center, Leiden, The Netherlands; C Noordam, Radboud University Medical Center Nijmegen, Nijmegen, The Netherlands; C Westerlaken, Canisius Wilhelmina Hospital, Nijmegen, The Netherlands; N J T Arends, E M Bannink, V H Boonstra, M Van Dijk, Y K van Pareren, T C J Sas, Erasmus Medical Center Sophia, Rotterdam, The Netherlands; H M Reeser and E C A M Houdijk, Juliana Children's Hospital, The Hague, The Netherlands; E J Schroor, Isala clinics, Zwolle, The Netherlands; J P C M van der Hulst, Zaans Medical Centre, Zaandam, The Netherlands; E J Sulkers, Walcheren Hospital, Vlissingen, The Netherlands; and M Jansen, Wilhelmina Children's Hospital, Utrecht, The Netherlands. 


\section{References}

1 Auwerx J. PPAR $\gamma$, the ultimate thrifty gene. Diabetologia 199942 1033-1049.

2 Altshuler D, Hirschhorn JN, Klannemark M, Lindgren CM, Vohl MC, Nemesh J, Lane CR, Schaffner SF, Bolk S, Brewer C, Tuomi T, Gaudet D, Hudson TJ, Daly M, Groop L \& Lander ES. The common PPAR $\gamma$ Pro12Ala polymorphism is associated with decreased risk of type 2 diabetes. Nature Genetics 200026 76-80.

3 Kilpelainen TO, Lakka TA, Laaksonen DE, Lindstrom J, Eriksson JG, Valle TT, Hamalainen H, Ilanne-Parikka P, Keinanen-Kiukaanniemi S, Lindi V, Tuomilehto J, Uusitupa M \& Laakso M. SNPs in PPARG associate with type 2 diabetes and interact with physical activity. Medicine and Science in Sports and Exercise $20084025-33$.

4 Jaquet D, Tregouet DA, Godefroy T, Nicaud V, Chevenne D, Tiret L, Czernichow P \& Levy-Marchal C. Combined effects of genetic and environmental factors on insulin resistance associated with reduced fetal growth. Diabetes 200251 3473-3478.

5 Tonjes A, Scholz M, Loeffler M \& Stumvoll M. Association of Pro12Ala polymorphism in peroxisome proliferator-activated receptor $\gamma$ with pre-diabetic phenotypes: meta-analysis of 57 studies on nondiabetic individuals. Diabetes Care 200629 2489-2497.

6 Masud S \& Ye S. Effect of the peroxisome proliferator activated receptor- $\gamma$ gene Pro12Ala variant on body mass index: a metaanalysis. Journal of Medical Genetics 200340 773-780.

7 Lindi V, Sivenius K, Niskanen L, Laakso M \& Uusitupa MI. Effect of the Pro12Ala polymorphism of the PPAR- $\gamma 2$ gene on long-term weight change in Finnish non-diabetic subjects. Diabetologia 2001 44 925-926.

8 Ek J, Urhammer SA, Sorensen TI, Andersen T, Auwerx J \& Pedersen O. Homozygosity of the Pro12Ala variant of the peroxisome proliferation-activated receptor- $\gamma 2$ (PPAR- $\gamma 2)$ : divergent modulating effects on body mass index in obese and lean Caucasian men. Diabetologia 199942 892-895.

9 Sas T, Mulder P, Aanstoot HJ, Houdijk M, Jansen M, Reeser M \& Hokken-Koelega A. Carbohydrate metabolism during long-term growth hormone treatment in children with short stature born small for gestational age. Clinical Endocrinology $2001 \mathbf{5 4}$ 243-251.

10 Leunissen RW, Oosterbeek P, Hol LK, Hellingman AA, Stijnen T \& Hokken-Koelega AC. Fat mass accumulation during childhood determines insulin sensitivity in early adulthood. Journal of Clinical Endocrinology and Metabolism 200893 445-451.

11 van Dijk M, Bannink EM, van Pareren YK, Mulder PG \& HokkenKoelega AC. Risk factors for diabetes mellitus type 2 and metabolic syndrome are comparable for previously growth hormone-treated young adults born small for gestational age (sga) and untreated short SGA controls. Journal of Clinical Endocrinology and Metabolism 200792 160-165.

12 Willemsen RH, Arends NJ, Bakker-van Waarde WM, Jansen M, van Mil EG, Mulder J, Odink RJ, Reeser M, Rongen-Westerlaken C, Stokvis-Brantsma WH, Waelkens JJ \& Hokken-Koelega AC. Longterm effects of growth hormone $(\mathrm{GH})$ treatment on body composition and bone mineral density in short children born small-for-gestational-age: six-year follow-up of a randomized controlled GH trial. Clinical Endocrinology 200767 485-492.

13 Fredriks AM, van Buuren S, Burgmeijer RJ, Meulmeester JF, Beuker RJ, Brugman E, Roede MJ, Verloove-Vanhorick SP \& Wit JM. Continuing positive secular growth change in The Netherlands 1955-1997. Pediatric Research 200047 316-323.
14 Usher R \& McLean F. Intrauterine growth of live-born Caucasian infants at sea level: standards obtained from measurements in 7 dimensions of infants born between 25 and 44 weeks of gestation. Journal of Pediatrics 196974 901-910.

15 Sas T, de Waal W, Mulder P, Houdijk M, Jansen M, Reeser M \& Hokken-Koelega A. Growth hormone treatment in children with short stature born small for gestational age: 5-year results of a randomized, double-blind, dose-response trial. Journal of Clinical Endocrinology and Metabolism 199984 3064-3070.

16 de Kort SW, Willemsen RH, van der Kaay DC \& HokkenKoelega AC. The effect of growth hormone treatment on metabolic and cardiovascular risk factors is similar in preterm and term short, small for gestational age children. Clinical Endocrinology 200971 65-73.

17 De Kort SW, Van Dijk M, Willemsen RH, Ester WA, Viet L, De Rijke YB \& Hokken-Koelega AC. Cardiovascular risk factors in parents of short children born small for gestational age. Pediatric Research 200864 91-96.

18 Cutfield WS, Bergman RN, Menon RK \& Sperling MA. The modified minimal model: application to measurement of insulin sensitivity in children. Journal of Clinical Endocrinology and Metabolism 199070 1644-1650.

19 Miller SA, Dykes DD \& Polesky HF. A simple salting out procedure for extracting DNA from human nucleated cells. Nucleic Acids Research 1988161215.

20 Verveke G \& Molenberghs G. Linear Mixed Models for Longitudinal Data. Berlin: Springer-Verlag, 2001.

21 de Kort SW, Mook-Kanamori DO, Jaddoe VW \& HokkenKoelega AC. Interactions between TCF7L2 genotype and growth hormone-induced changes in glucose homeostasis in small for gestational age children. Clinical Endocrinology In press DOI: $10.1111 /$ j.1365-2265.2009.03635.x.

22 Eriksson JG, Lindi V, Uusitupa M, Forsen TJ, Laakso M, Osmond C \& Barker DJ. The effects of the Pro12Ala polymorphism of the peroxisome proliferator-activated receptor- $\gamma 2$ gene on insulin sensitivity and insulin metabolism interact with size at birth. Diabetes $2002512321-2324$.

23 Ek J, Andersen G, Urhammer SA, Hansen L, Carstensen B, BorchJohnsen K, Drivsholm T, Berglund L, Hansen T, Lithell H \& Pedersen O. Studies of the Pro12Ala polymorphism of the peroxisome proliferator-activated receptor- $\gamma 2(\operatorname{PPAR}-\gamma 2)$ gene in relation to insulin sensitivity among glucose tolerant caucasians. Diabetologia 200144 1170-1176.

24 Stumvoll M, Wahl HG, Loblein K, Becker R, Machicao F, Jacob S \& Haring H. Pro12Ala polymorphism in the peroxisome proliferator-activated receptor- $\gamma 2$ gene is associated with increased antilipolytic insulin sensitivity. Diabetes $2001 \mathbf{5 0}$ $876-881$.

25 Buzzetti R, Petrone A, Caiazzo AM, Alemanno I, Zavarella S, Capizzi M, Mein CA, Osborn JA, Vania A \& di Mario U. PPAR- $\gamma 2$ Pro12Ala variant is associated with greater insulin sensitivity in childhood obesity. Pediatric Research 200557 138-140.

26 Yliharsila H, Eriksson JG, Forsen T, Laakso M, Uusitupa M, Osmond $\mathrm{C}$ \& Barker DJ. Interactions between peroxisome proliferator-activated receptor- $\gamma 2$ gene polymorphisms and size at birth on blood pressure and the use of antihypertensive medication. Journal of Hypertension 200422 1283-1287.

Received 9 September 2009

Accepted 1 October 2009 